\title{
new television seal of approval holders
}

Michael L. Pass, Shreveport, Louisiana 570

Mark D. Maggipinto, Fort Meyers, Florida 571

Joseph R. Calbreath, Eugene, Oregon 572
Peter G.J. Parsons, Portland, Oregon 573

Michael Maguire, Evansville, Indiana 574

Mark David Wilkinson, Colorado Springs, Colorado 575

\section{new certified consulting meteorologists}

David J. Wackter, Manchester, Connecticut 459

Patrick T. Gannon, Lyndonville, Vermont 460

\section{Corrigendum}

Bradley J. Edwards was listed incorrectly as Bradley J. Meyers as a new television seal of approval holder in the November 1989 Bulletin.
William Groot, Concord, Massachusetts 461

\section{MONSOONS \\ Edited by \\ Jay S. Fein and Pamela L. Stephens}

This comprehensive volume covers the monsoon from many perspectives, including: the influence of the monsoon on traditional culture; an economic analysis of the value of weather and climate data in developing countries; the evolution of the concept of the monsoon as a weather and climate systems from the early mariners to today's scientists; a most thorough treatment of monsoon variability on paleoclimate time scales; an in-depth look at topographical influences on monsoons; ocean-monsoon interactions, and interactions of monsoons with other global weather and climate events; the latest information on the

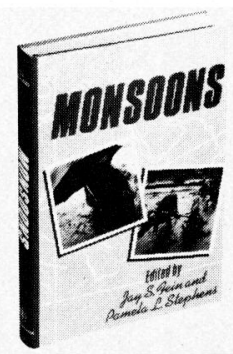

tools being used to predict the variability of monsoons.

Illustrated with ocean circulation charts, data tables on long-term statistice of monsoon precipitation and its variability, and tensive bibliographies, Monsoons is the first work to take a broad, multidisciplinary look at this dramatic product of nature. An ideal sourcebook for meteorologists and climatologists, oceanographers, environmental scientists, folklorists, and policymakers in monsoon regions-for anyone interested in a phenomenon that so greatly affects so much of mankind.

To order please send $\$ 81.95$ plus $\$ 3.00$ postage and handling to:

\section{AMERICAN METEOROLOGICAL SOCIETY 45 BEACON STREET BOSTON, MA 02108}

